\title{
LUA E ESTRELA: EXPERIÊNCIA E UNIVERSALIDADE NAS VIAGENS DE AFONSO ARINOS DE MELO FRANCO
}

Em geral, concebemos as viagens como um deslocamento no espaço.

É pouco. Uma viagem inscreve-se simultaneamente no espaço, no tempo e na hierarquia social. Cada impressão só é definível se a relacionarmos de modo solidário com esses três eixos, e, como o espaço possui sozinho três dimensões, precisaríamos de pelo menos cinco para fazermos da viagem uma representação adequada (Lévi-Strauss, Tristes trópicos, p. 8I).

\section{EM NOITES DE LUA CHEIA}

Como se sabe, a obra de Afonso Arinos de Melo Franco impõe um grande número de desafios aos seus intérpretes, quer seja por sua extensão - afora os livros, são quase inumeráveis seus artigos, conferências, discursos e intervenções na cena pública nacional e internacional ${ }^{1}$-, quer pelo fato de o autor ter transitado por temáticas variadas, áreas do conhecimento e formas discursivas diversas. Procurarei enfrentar essas dificuldades lidando com o pensamento deste intelectual mineiro e homem do mundo através dos seus relatos de viagens ${ }^{2}$ para destacar alguns aspectos pouco explorados pela bibliografia pertinente, que são os do seu diálogo com o Modernismo e da sua relação com a cultura nacional.

As viagens em questão serão as que Afonso Arinos realizou no começo da década de 1920 à Europa e aquela feita na Semana Santa de I936, a Ouro Preto. O relato da primeira viagem e a reflexão sobre a experiência e o con- 
tato com a cultura clássica, principalmente greco-romana e francesa, estão em seus livros A alma do tempo e Amor a Roma. A segunda viagem é relatada em Roteiro lírico de Ouro Preto, realizada em companhia de Pedro Nava, João Gomes Teixeira e Francisco de Assis Magalhães Gomes e, embora de forma não explícita, dialoga com a viagem feita por Mario de Andrade, Blaise Cendras, Oswald de Andrade e Olivia Guedes Penteado às cidades históricas mineiras uma década antes.

Inicio este trabalho chamando a atenção para que um dos seus pressupostos é a ideia de que a relação do homem público que foi Afonso Arinos com o Modernismo e a sua concepção da cultura nacional não pode ser interpretada adequadamente sem que levemos em consideração o aspecto da formação da subjetividade que o relato das suas experiências evidencia. Além de uma estratégia interpretativa, este aspecto fica ainda mais destacado quando estamos lidando, como é o caso, com livros de memórias e de impressões de viagem, e apenas secundariamente, e de forma subordinada a estes, com textos de interpretação histórica e sociológica. Ao longo deste texto, portanto, irei me referir à ideia de que as viagens e os relatos estão implicados em uma modelagem do self que ocorreria pelo menos em duas direções diferentes, embora complementares, e marcadas por formas de sociabilidade também distintas. Em uma direção há um predomínio da persona pública do autor, fortemente influenciada pelos laços familiares; em outra, sobressaem avaliações mais pessoais e menos preocupadas com a representação de um ethos familiar. Como se verá a seguir, essas distinções, cruciais tanto na percepção dos lugares para onde se deslocou como para a formulação de uma autopercepção de si, permitem lançar luz sobre o modo como o autor enfatizou, ora a vida pública, ora a vida privada e a subjetividade.

A primeira via de automodelagem se sustentava a partir de uma certa percepção de si e de sua família como patrimônio cultural da nação, e pode ser notada na afirmação de uma espécie de indistinção entre a vida pública e a vida privada, algo que caracterizava a atuação de seus familiares mais renomados, em cujo convívio sua personalidade foi formada.

Essa mistura entre o público e o privado, tipicamente pré-burguesa, essa lógica vivida por Afonso Arinos o faz, desde cedo, julgar e reagir enfaticamente aos episódios com os quais se depara como indivíduo anônimo, reclamando o reconhecimento público, não de si, mas das virtudes cívicas e civilizacionais de seu clã e de sua linhagem. A postura demonstrada por Afonso Arinos é a de um homem orgulhoso de sua estirpe e que se patenteia em uma retórica na qual fica evidente que, como se diz no ballet, "il faut cacher l'effort":

creio que por ter convivido, desde pequeno, em casa de meu pai, com gente notória e por ali ter assistido a acontecimentos importantes; e também por lido muito, sobre fatos, cenas e vidas realmente grandiosas, muito acima do que sou ou do que vivi, apodera-se de mim, invariavelmente, nas horas culminantes da minha própria exis- 
tência, esse sentimento que não é de desprezo, nem de indiferença, nem de incompreensão, mas de naturalidade (Franco, I979a: 63, ênfase minha).

"Naturalidade" que, no entanto, deverá ser interpretada como mais um dos artifícios que constituíam o ideal de conduta dos Melo Franco e de seu círculo de relações. ${ }^{3}$

Contudo, foi a partir dessa preponderância do público sobre as dimensões do privado e da intimidade - os únicos lugares onde a experiência da subjetividade é possível são o interior do quarto em Copacabana ou o leito dos sanatórios suíços - que, para um rapaz da sua origem, o estabelecimento de uma relação íntima com o estrangeiro, especialmente com a Europa, tornou-se algo absolutamente essencial, porquanto expectativa de seu grupo familiar em detrimento daquilo que poderia constituir a expressão exclusiva dos seus interesses individuais. ${ }^{4}$

Por denotar um claro sentido formativo, é difícil deixar de associar essas viagens à Europa de Afonso Arinos a uma espécie de Grand Tour, ${ }^{5}$ ou seja, ao modo como ficou conhecido o longo ciclo de viagens que, desde o século XVII até meados do XIX, mas, sobretudo no século XVIII, foi realizado por parte dos jovens da aristocracia inglesa e da Europa continental às fontes da cultura clássica. Percorrendo os principais e mais tradicionais destinos (França, Suíça e, sobretudo, Itália), Afonso Arinos também vai à Europa como se disso dependesse uma formação necessária para a vida pública. Ou seja, tudo o que é experimentado está a serviço de sua persona pública, vivida como artifício e autoconstrução consciente, algo de que suas memórias são o testemunho. Por outro lado, nada mais distante da ideia de aventura (ver Simmel, 2002) que este Grand Tour de Afonso Arinos: ele é vivido não como um momento de rompimento com um fluxo de experiências cotidianas, mas como a constatação e a confirmação do já sabido e valorizado. Este contraste será retomado quando tratarmos do que considero seu grand tour interno, a viagem a Ouro Preto.

Já a viagem à Europa, da qual passo a me ocupar a seguir, foi feita pelo autor aos I9 anos, juntamente com a família, acompanhando o seu pai que, desde 1923, entrara na fase internacional da sua carreira e agora, em I924, fora nomeado para o posto de embaixador, o primeiro, junto à Liga das Nações, fixando residência em Genebra. Assim, durante os anos de I924 e I925, Afonso Arinos circularia pela Europa, ou, mais exatamente, pelos ambientes frequentados por uma aristocracia do espírito, da qual faziam parte brasileiros e europeus e que tinha como linguagem comum a literatura.

Coincidentemente, se a formação oferecida pela Faculdade de Direito do Distrito Federal, na qual ingressa em I922, era "predominantemente literária" (Franco, I979a: 73), ${ }^{6}$ Arinos comentava que 
[p]ara o meu amadurecimento intelectual, o mais importante que recolhi na minha experiência de Genebra, mais ainda do que as conversas com Montarroios ou as visitas a Robert de Traz, foi o curso de Literatura e Estilística Francesa que fiz com o Professor Séchaye [...] da douta Universidade local. Não se pode conceber tipo mais representativo do magistério superior europeu, do que o meu velho professor. Ele parecia um mestre do século XIX, um Sylvestre Bonnard, um Bergeret, tão carinhosamente fixados por Anatole France (Franco, 1979a: II5).

Neste sentido, parece não haver solução de continuidade entre sua formação brasileira e europeia, tratando-se mais de um acréscimo de sofisticação, de refinamento do jovem intelectual que nesse meio tempo, entretanto, já oscilava entre o gosto pela cultura clássica e a participação no movimento modernista. 7

Analisando mais detidamente esse ethos que marca a sua relação com a cultura europeia e com a constituição de uma concepção do nacional, veremos tratar-se de uma extensão do ethos familiar que prevalecia sobre as experiências mais imediatas de Afonso Arinos, em que toda e qualquer experiência seguia modelos bastante rígidos de formação, desde leituras, destinos e roteiros de viagens até padrões de etiqueta e círculos de relacionamento recomendados. Mas será, desde logo, sob a perspectiva de uma tensão com esta tradição familiar que proponho pensar a sua relação com a Europa e com o primeiro Modernismo, crítico da civilização ocidental.

No momento em que realiza esta viagem à Europa, Afonso Arinos, como acabei de mencionar, demonstra razoável controle da cultura ocidental, incorporada como parte da herança de um patrimônio intelectual familiar. Ele descreve, assim, uma vivência em uma espécie de sociabilidade aristocrática a qual o pai está associado, sociabilidade que dignifica os valores da erudição clássica tanto nas artes quanto na ciência, valores que se concentrariam e transmitiriam pela linhagem dos Melo Franco.

A erudição precocemente adquirida e a influência paterna saltam das páginas de seu livro de memórias em que relata esta viagem de I924. Se as leituras dos Lusíadas pelo pai, ao lado do túmulo do poeta, nada dizem, em conteúdo, ao filho, a reencenação de Afrânio do comportamento de viajantes de outras épocas não é negada na forma. "O encontro com a França foi para mim, como para todo brasileiro da minha formação, na verdade, um reencontro" (Franco, I979a: 96). Isto é, a mesma reverência do pai diante do legado português era adotada por seu filho quando o que estava em jogo era a França, a ponto de, no tombadilho do navio que o levava então à Europa, julgar-se um Taine e reconhecer-se um adolescente afrancesado, embora já contaminado pela influência do Modernismo, que havia se transformado em umas das fontes de conflito com o pai.

Cinquenta e oito anos mais tarde, Afonso Arinos abre seu Amor a Roma, obra de I982, com a seguinte lembrança: "Certa noite de abril de I925 tomei, 
em Genebra, o carro-dormitório do expresso de Roma. Aos dezenove anos, fazia aquela viagem por sugestão de meu pai [que,] além de afastar-me do degelo alpino [...] invocava outros motivos para a viagem. Segundo ele impunha-se, na minha idade, conhecer Roma. Na sua maneira de ver, meu entendimento era suficiente para absorver o espetáculo romano" (Franco, I982: 22).

Como acabei de assinalar, Afonso Arinos adotava uma postura meio discordante, mas ao mesmo tempo obediente ao pai e aos costumes de sua classe, e neste sentido penso que, para compreender o contexto por intermédio do qual ele incorporava a cultura clássica, devemos começar por analisar a tensão entre o tipo de sociabilidade do qual o seu pai, Afrânio de Melo Franco, era um representante e o modo como o jovem Afonso Arinos recebia esta influência.

Político de destaque no Rio de Janeiro e em Minas Gerais - além de desempenhar um papel proeminente na diplomacia brasileira -, Afrânio de Melo Franco exercia ambas as atividades de forma autocrática, estabelecendo relações bastante hierarquizadas que inviabilizavam qualquer tipo de discordância mais aberta e chegavam, inclusive, a impedir considerações de cunho mais pessoal que transbordassem os limites da cerimônia. Em A alma do tempo, os aspectos mais privados da personalidade do seu pai parecem esvaziar-se diante de sua figura pública, quando não se constituem em um modo peculiar, característico de sua atuação política.

Esta ênfase na vida pública infere-se, entre vários outros exemplos, da maneira pela qual era gerida a própria casa, que, em vez de se definir como um local de privacidade e intimidade característico do mundo burguês, se torna progressiva e acentuadamente, após a morte da esposa, uma instituição da vida política brasileira. Como podemos observar na passagem transcrita abaixo, Afonso Arinos vivenciou desde muito cedo essa atrofia do espaço doméstico.

[Em 1922] As reuniões, conciliábulos, providências, se sucediam em torvelinho. [...] A casa vivia repleta de congressistas, militares, jornalistas, emissários daqui e dali. No tempo das cartas falsas, então, era um inferno. Nós, os rapazes, que tínhamos quartos embaixo, onde também estava a biblioteca, não podíamos ficar em paz. Certa manhã muito cedo Virgílio acordou assombrado, com Paulo de Frontin e meu pai cochichando, sentados ao lada da cama dele. À falta de outro local tinham-se refugiado ali (Franco, 1979a: 75).

São raras as efusões de afeto do patriarca, e seu gênio é retratado como de difícil trato. Vide o relato do episódio ${ }^{8}$ ocorrido no saguão do Grande Hotel de Belo Horizonte, por volta de I928, em que o pai demonstra o que o filho considera seu maior "defeito de temperamento [...] que era o descontrole completo dos nervos, quando se sentia ferido ou desconsiderado": assim, ao receber os cumprimentos de um desafeto político, "desgovernou-se e recebeu o recém-chegado da forma mais áspera e violenta” (Franco, I979a: 20I). 
Neste sentido, a dureza que tanto o Afonso Arinos de I928 quanto o de 1978 considera um defeito, seria, portanto, uma espécie de obrigação para os padrões de sociabilidade sustentados pelo seu pai.

Poucos também são os relatos de momentos de relaxamento e de intimidade, e mesmo estes estão emoldurados pela política e pelo cerimonial. Em I93I, ministro do exterior, Afrânio de Melo Franco chegara a Belo Horizonte "talvez decidido a mostrar sua força" (Franco, I979a: 22).

\begin{abstract}
Veio com secretários e com um ajudante-de-ordens todo brilhante no uniforme impecável, nos requintes dourados de jovem oficial meio prussiano. Durante um dia ou dois, a nossa casa tosca [em que Afonso Arinos e sua esposa Anah viviam provisoriamente], de móveis alugados, tornou-se o centro de encontros e visitas, e eu sentia, divertido, o discreto espanto do major peitudo, de cintura fina, luvas, garboso nos seus alamares, diante daquela instalação pouco decorosa do "filho do Sr. Ministro de Estado". Meu pai ria comigo, às escondidas (Franco, I979a: 22, ênfase minha).
\end{abstract}

Ou seja, Afonso Arinos descreve uma vivência numa espécie de sociabilidade aristocrática à qual o pai está associado, sociabilidade que dignifica os valores da erudição clássica tanto nas artes quanto na ciência, e que se concentrariam e transmitiriam, como foi mencionado acima, pela linhagem dos Melo Franco.

Contudo, se é evidente que estes valores são prezados e extremamente cultivados, seu aspecto performático, com ênfase no comportamento, na etiqueta e no desempenho das boas maneiras recebe enorme destaque na narrativa de Afonso Arinos sobre esta época de sua vida.

Exemplo disso é a oposição que ele estabelece entre a sua própria família e a aristocracia genebrina de "tradição calvinista, [que] era muito fechada e se isolava nos altos da Corraterie, na requintada Avenue des Pins que era uma espécie de Faubourg Saint-Germain provinciano" (Franco, I979a: I06) O contraste com a forma como os Melo Franco são caracterizados, como uma espécie híbrida e relativamente aberta de aristocracia de corte, é evidente: a casa tornou-se aos poucos e "sem esforço da nossa família, [...] uma espécie de centro social do meio diplomático" (Franco, I979a: I07, ênfase minha). A família Melo Franco, nas palavras do diplomata uruguaio "Guani", era "ideal pelas suas virtudes, por sua elegância e por suas tradições de fidalguia e amável hospitalidade" (Franco, I979a: p. I07).

Vale a pena sublinhar que a narrativa de A alma do tempo é prolixa em adjetivações positivas para tudo e para todos, lugares e pessoas, como reza essa modalidade de experiência cortesã da qual o pai é o mais acabado modelo para o filho aprendiz:

Vejamos, por exemplo, a história exemplar relatada por Afonso Arinos por ocasião de sua visita ao casal Robert de Traz e a condessa de Nosilles, "pertencente à mais alta e autêntica aristocracia genebrina". Tendo seu motorista, por equívoco, retornado à cidade mais cedo e sem avisá-lo, o jovem 
Afonso Arinos recorre ao mordomo da casa para que lhe peça um carro por telefone, mas este decide comunicar o fato aos patrões. Gentis e hospitaleiros, dando mostras "da extrema polidez da sociedade aristocrática europeia", ambos insistem para que ele os aguardasse, pois também se deslocariam para a cidade naquela noite.

Os anfitriões do "Reposoir" levaram-me no seu automóvel até à porta de casa e eu fiquei muito satisfeito quando, contando o pequeno caso a meu pai, ouvi dele instruções para enviar à Senhora Robert de Traz, no dia seguinte, as mais belas flores que pudesse obter naquele princípio de inverno. "Mande as mais caras; será fora da sua mesada" - a tranquilizou-me meu pai, sempre galante com as damas (Franco, I979a: II5).

Além disso, a delegação permanente da embaixada brasileira é apresentada como composta por velhos amigos e antigos colaboradores, com quem Afonso Arinos termina por manter a mais cordiais relações ao longo de sua vida. Descrevendo uma rede de relações em que deveres, obrigações e vínculos pessoais são a marca, ele observa que:

Os secretários eram Hildebrando Acioli e Silvio Rangel de Castro. O primeiro prosseguiu, sempre em linha ascensional, a luminosa carreira de internacionalista, na qual hoje se destaca como autoridade mundial. O segundo continuou, até o posto de embaixador, a carreira diplomática, em que se aposentou depois de longos serviços. Sílvio era muito ligado aos Rodrigues Alves, sendo seu pai nascido em Guaratinguetá e íntimo amigo do Conselheiro. Essa circunstância estreitou os nossos laços de amizade, depois de meu casamento com uma das netas do ex-presidente. Em certa época, veio servir, igualmente como secretário, Heitor Lira, removido de Londres. Não me recordo se o futuro embaixador em Portugal já se preocupava, então, com a história do nosso Império, de que se tornou, depois, exímio cultor (Franco, I979a: I08).

Enfim, a narrativa das condições de existência da sua família na Suíça, da qual não se dissocia senão em seus momentos de reclusão, de rapaz solitário, sem amizades do mesmo gênero e idade, é caracterizada por uma ênfase na tradição, na etiqueta e nos aspectos mais públicos da sociabilidade prezados pelos Melo Franco.

A valorização da genealogia como estratégia para evitar a dispersão endêmica do patrimônio permite, dessa forma, que o objetivo da ampliação da influência familiar se cumpra pela extensão, a um grupo variado e seleto de intelectuais, políticos e diplomatas, brasileiros e estrangeiros, de uma aura de enobrecimento e distinção. É como se o recurso à adjetivação dignificante e o elogio de um tipo determinado e preciso de ação, capaz de estimular um desempenho compatível com um conjunto de estritas regras de etiqueta tivessem o poder de nobilitar o mundo.

É importante assinalar, a esta altura, que a sua relação com o pai, marcada por certa ambiguidade e um limitado antagonismo, será crucial para dotar de proximidade ou de distância sua relação com a cultura europeia. 
Quero me referir aqui a um conjunto de episódios, narrado em A alma do tempo, no qual o afastamento do autor em relação ao estilo paterno é ressaltado. Naturalmente, as diferenças aparecem em diversas áreas da vida, mas, além das questões de "temperamento" do pai e das suas consequências públicas e privadas, são uma visão própria da política nacional e uma certa autonomia na definição da carreira por parte do filho as que mais evidenciam os antagonismos entre ambos.

Para falar destes últimos, começo com uma segunda apreciação daquele caso do saguão do Grande Hotel. Naquele momento, tornava-se flagrante o desconcerto dos filhos diante do descontrole do pai: a atitude de lealdade de Afonso e Virgílio não esconde a muda censura. Lembrando o contexto do episódio, Afonso Arinos comentará: "o incidente não deixava meu pai em boa posição, pois lhe revelava a por vezes inconsiderada impulsividade, traço de caráter nem sempre bem recebido em Minas Gerais" (Franco, I979a: 20I).

A sequência acerca dos desdobramentos deste incidente, cujo pivô é o próprio Afonso Arinos e sua crônica desastrada em O Jornal, que, como já notamos, alimenta as forças dos inimigos políticos de Afrânio em Sabará, é repleta de ambiguidades e, de certa forma, marca o momento de ruptura de Afonso Arinos com a vida pública mineira e seu retorno para o Rio de Janeiro.

Aquilo me fez transbordar as reservas de boa vontade e obediência. Senti que não aguentava mais. Meu pai começou a se aperceber disso, como deixa claro uma carta recebida de Anah. A Virgílio ele confidenciou que eu era "inteiramente inadaptável" ao novo meio. Porém, inteligente e tolerante, sobretudo em relação aos filhos, não ofereceu dificuldades maiores quando, numa das curtas viagens que fiz ao Rio, comuniquei-lhe minha intenção decisiva de regressar. Limitou-se a divergir da decisão, que considerava prejudicial ao meu futuro. Homem típico da Primeira República, ele tinha uma mentalidade federal muito acentuada; não compreendia que, sendo alguém mineiro, pudesse fundar a sua vida pública fora de Minas. Argumentou, exemplificou com o seu próprio caso. Tudo o que era, tudo o que havia feito, dizia-me, fora o resultado e o desenvolvimento dos anos preparatórios que passara em Minas Gerais, como promotor, advogado, professor e deputado estadual. Segundo ele, eu nunca poderia fazer nada, partindo do Rio, a não ser vida burocrática ou profissional, ambas custosas, demoradas e precárias. Eu ia afundar na mediocridade carioca, na concorrência da grande cidade. Iria apagar as minhas qualidades na simples disputa do ganha-pão. Se era isso que eu queria, que o fizesse; e que fosse pessoalmente feliz. Mas que desse adeus à vida pública (Franco, 1979a: 199, ênfases minhas).

Esta longa citação justifica-se, pois se trata de uma passagem carregada de dramaticidade e que soa como um ato de deserdação. Afrânio de Melo Franco, o texto é explícito, não via para Afonso Arinos possibilidades de exercício de vida pública, de reconhecimento público, fora do jogo em que ele próprio estabelecia as regras. Soa, portanto, como ironia, que ele não tenha oferecido "dificuldades maiores" e que tenha demonstrado "tolerância" e capacidade para o diálogo para o que considerava uma vida medíocre e indigna para o filho. 
Em I960, data dessas anotações em A alma do tempo, Afonso Arinos atenta para a ironia do fato de que "a mitigação do federalismo brasileiro, devida aos partidos, veio dar-me, precisamente no Rio, a minha maior vitória política" (Franco, I979a: 202), contra as previsões do pai em I928. Conforme analisa, seu pai não entendera que a única maneira de o seu nome continuar politicamente seria adequando-se às novas regras da política nacional.

Conforme acabamos de ver, Afonso Arinos lida com a crise familiar, instaurada por sua saída da promotoria de Belo Horizonte, tentando uma outra via de participação na vida pública, e isso significará tanto produzir-se, no plano subjetivo, como individualidade autônoma, quanto, objetivamente, construir uma relação com o mundo distinta daquela que vinha sendo modelada por seu pai. Mas a subordinação não desaparece inteiramente. Há, inclusive, um aspecto que pontua a narrativa de A alma do tempo, que é o da dependência econômica. A imensa rede de relações de que dispõe não elimina as dificuldades financeiras eventuais e a necessidade de recorrer à família e, em especial, ao pai.

Em I932, por exemplo, ele é designado para servir, como secretário da delegação brasileira, à Conferência Internacional do Desarmamento, que se reunia em Genebra. No comentário que faz do acontecimento, gratidão e escrúpulos se misturam: "Meu pai me nomeara para a função, pensando em estimular-me com trabalho e, provavelmente, em socorrer-me com alguns francos suíços. Na verdade eu era um secretário barato, pois não precisava pagar a viagem, do e para o Brasil" (Franco, I979a: 243).

Contudo, já desde I928, um conjunto de novos problemas surgira para Afonso Arinos: os atropelos da mudança para a nova residência em Belo Horizonte, após seu casamento com Anah; a necessidade de adaptação às suas funções de promotor no serviço público; as desavenças entre os grupos políticos regionais; o nascimento e as dificuldades dos primeiros meses de vida do seu filho; o excesso de trabalho; tudo isso agrava seu estado de saúde e impõe, no início da primavera de I93I, uma outra temporada na Suíça, onde ficará até a cura da tuberculose, até o fim do verão de 1932.

Neste momento de sua vida, Afonso Arinos é como que lançado em uma situação decisiva. Para alguém com a fortuna intelectual que possuía, encontrar-se em uma circunstância que acentua as ideias de precariedade e de transitoriedade - e não a de perenidade e de eternidade garantidas pela linhagem da família - importará uma mudança de ênfase que, daqui por diante, o levará a operar com uma nova concepção de patrimônio e da maneira como este deve ser passado às outras gerações. Fortalece-se nele, portanto, uma outra concepção, diferente daquela com que vínhamos operando, pela qual algo, para ser legado e para perdurar, precisa incorporar a novidade: qualquer patrimônio, para não se fossilizar e desaparecer, deverá passar por um trabalho de renovação a fim de que possa retornar, ampliado e transformado, à tradição comum. 
Acredito que a viagem de I93I, para cuidar da saúde, constituiu uma experiência bastante importante para modular a influência paterna e o peso do patrimônio familiar, mas também para atribuir um outro sentido à viagem do autor, o de uma subjetividade que se transforma durante a experiência.

Primeiro, porque o motivo da viagem, a doença, tanto acentua o senso de precariedade e transitoriedade, como também enfatiza sua individualidade e suas sensações. Desde logo, vejamos o choque da descoberta da tuberculose:

Aquilo era comigo e não com outro. Mas eu é que me sentia outro e não aquele que entrara uma hora antes no escritório. Eu era outro, feito para receber aquele impacto que o eu de antes não aguentaria; um homem novo, inaugural, esquecido de todo o resto, olhando fixamente para a luz redentora, que vislumbrava ao longe (Franco, 1979a: 218)

A partir daí, ele estabelecerá relações com um grande número pessoas envolvidas com a doença, médicos, enfermeiras e pacientes, pessoas que estavam fora do círculo paterno de influência. Um episódio desta viagem, mesmo que nele não estivesse diretamente envolvido como paciente, é ilustrativo do argumento. Anah adoece no navio, a caminho da Suíça, e seu tratamento exigia decisões rápidas que o levaram a confiar em um médico argentino que desconhecia e a opor-se abertamente à autoridade do comandante do navio que não queria permitir a intervenção cirúrgica, que se fazia necessária e urgente. "Eu tinha 25 anos, o inglês mais de 6o. Olhou-me com surpresa e algum desprezo. Era o olhar de um gentleman para o colonial [ele ainda pensavam assim em I93I]. [...] é possível que o notável britânico soubesse quem eu era, ou melhor, o posto que ocupava meu pai, e não quisesse criar complicações entre a companhia e o então ainda prestigioso ministro do Exterior da Revolução" (Franco, I979a: ênfases minhas). Note-se que o embate entre a autoridade do médico do navio e as vontades de Anah e de Afonso acabaria por relativizar o vínculo com o pai, pois, mesmo que contribuindo para um desfecho favorável da situação, a intimidação do médico inglês diante da alta posição de Afrânio no governo brasileiro, parecia colocá-lo sob suspeita aos olhos do filho, ao revelar uma postura menos digna, ao passo que o médico argentino agira de forma independente às considerações de status, levando em conta apenas o bem-estar e a cura de sua paciente. Nesse sentido, embora ainda tivessem força, tanto a identidade com o pai como a ideia de seu prestígio inamovível começavam a se modificar em alto-mar e, pouco a pouco, nos sanatórios suíços, o mundo da medicina e dos seus profissionais mostrava-lhe critérios e procedimentos próprios, diferentes daqueles dos aprendera até então.

Também fora do círculo de influência paterno está a relação mais próxima com Anah na Suíça, pois o filho ficara com os avós maternos no Rio. Como dirá, "o sanatório era como um navio. Só Anah me liga à realidade, à 
vida". Embora não haja espaço aqui para maiores voos no sentido de se ampliar a compreensão do papel de Anah na vida pública do seu marido, convém frisar, entretanto, que ela teve uma importância fundamental para este movimento de ênfase na individualidade e, consequentemente, para que ele viesse a sustentar uma sociabilidade mais aberta e flexível que a do pai.

Por fim, e não menos importante, há, nesta viagem à Suíça de I93I, uma relação de outro tipo com a Europa (ou com uma Europa de outro tipo), pois o que ele vê de sua janela e com o que precisa se colocar pessoalmente em relação são os Alpes, a pequena cidade de Montana e seus habitantes. Resultado visível desta experiência são as anotações das idiossincrasias locais e das suas comparações com as brasileiras. Por exemplo, a respeito da diferença do valor das vacas para suíços e brasileiros comenta que "os companheiros de sanatório mal disfarçavam a polida incredulidade, ou o pasmo, quando ouviam de mim referências aos primos sertanejos, e aos rebanhos de muitos milhares de cabeças que possuíam e possuem, espalhados pelos campos marginais do Urucuia ou do Paracatu. Consideravam esses relatos verídicos como simples gabolice latino-americana" (Franco, I979a: 235). Se no início do comentário, ele ainda acredita que "para se ter ideia do que representa uma vaca na vida de um camponês europeu, basta reler aquela página autobiográfica de Eckermann, no início de suas Conversações com Goethe", a curiosidade o instiga, entretanto, a entrar em um dos pequenos chalés de madeira no alto da montanha, onde os pastores de Montana dormem junto com os animais. E, prosseguindo a leitura, podemos verificar a inversão que faz da relação entre conhecimento e experiência: "Quando li o forte romance de Ferreira de Castro, A lã e a neve, lembrei-me logo daqueles rudes suíços dos plans-mayens do Valais" (Franco, I979a: 325).

Vemos que a afirmação de que basta "reler Eckermann" já não deveria ser levada tão ao pé da letra. Assim, todo o relato sobre a estadia em Montana é pontilhado de observações aleatórias: menciona o dialeto local, a vestimenta das mulheres, seus hábitos domingueiros, os detalhes da arquitetura do sanatório e dos hotéis, as pessoas anônimas com quem se encontra, os aspectos do clima e das estações. As anotações se sucedem como se ele tivesse perdido a moldura tradicional e mundana através da qual poderia entender aquela realidade

Neste sentido, o que está em jogo, quando se trata de avaliar esses diferentes modos de Afonso Arinos lidar com a experiência no estrangeiro é a maior ou menor inflexão da autoridade paterna sobre o filho. Se, por um lado, como acabamos de ver, a distância com relação ao pai lhe permite criar uma nova perspectiva em relação à Europa, por outro, esta visão, quando formada pelas mãos do pai ou associada a ele, tornava-se esquemática, livresca ou meramente reprodutora do ambiente familiar. 
Duas passagens de A alma do tempo tornarão o argumento mais claro.

Tomamos um daqueles trens do sul, vagarosos e líricos, que atravessam a Provença, rumo a Dijon. Meu pai fez reservar um carro, à boa moda mineira, e eu me senti um pouco como no tempo em que a nossa numerosa família se deslocava, em vagão especial, de Belo Horizonte para o Rio, ou vice-versa. Nem faltava o pormenor provinciano da malotagem [...]. No carro-dormitório ríamos e cantávamos, como se estivéssemos entre Queluz e Juiz de fora. Meu pai, a princípio irritado, cedeu enfim ao bom humor geral. E o trenzinho provençal resfolegava, parecido com aquele de que fala Alphonse Daudet "ruisselant de vins et des chansons" ( Franco, I979a: 97).

Trata-se, aqui, do caso das associações que faz no trajeto de Bordeaux a Genebra e, como podemos observar, na ocasião desta viagem era muito pequena a distância que o autor julgava haver entre a Minas Gerais familiar e a região francesa da Provença.

Outra passagem ilustrativa está em Amor a Roma, na qual revela os acontecimentos imediatamente anteriores à viagem da família, em I924; é quando se refere à sua ligação com o Modernismo e, sobretudo, à tentativa de aproximar seu pai dos intelectuais que compunham este movimento.

Ficamos sabendo, ali, que Afonso Arinos vai à Roma em I924 por sugestão do pai. Conforme relata,

na sua maneira de ver, meu entendimento era suficiente para absorver o espetáculo romano. Tanto mais absorvente, quanto a espontaneidade emotiva deveria conferir coloração pessoal às novas experiências. Em resumo, pelo que me deu a entender Carlos Magalhães de Azeredo, amigo de mocidade de meu pai e embaixador no Vaticano (a quem ele escrevera para que fosse meu guia romano), era importante que eu sentisse Roma, antes que viesse a compreendê-la (Franco, I982: 22).

Contudo, antes de qualquer incentivo à autonomia, o que o velho Afrânio esperava era dissolver o "preconceito modernista" adotado então pelo filho, o qual avaliará mais tarde que, em sua "inciência dos dezenove anos [,] guardava do modernismo os preconceitos e não as qualidades" (Franco, I982: 44) O projeto do pai, supostamente, teria tido êxito imediato, pois se Afonso Arinos vinha aderindo à "alegre irresponsabilidade de espírito dos fundadores da Klaxon, a revista de vanguarda do movimento, que considerava atitude cultural a substituição dos monumentos históricos por 'higiênicos' edifícios de cimento", suas ideias passaram por uma certa revisão ao passear pelas as ruas de Roma com Magalhães de Azeredo, posto que "todo ele era recordação viva de Leão XIII, Eça de Queiróz, Ramalho Ortigão, D’Annnunzio, Heredia, Anatole France, Rio Branco, Joaquim Nabuco, Machado de Assis... Essas sombras nos cercavam pelas vias ilustres da urbe" (Franco, 1982: 47).

Entretanto, se esta "flanêrie" romana auxilia Afonso Arinos a moderar, a temperar a sua adesão às propostas mais demolidoras típicas dos movimentos de vanguarda, isto não importou, definitivamente, uma ruptura com a "geração modernista". Ao contrário, o que parece se afirmar aí é o seu 
vínculo com uma outra definição de modernismo mais próxima a Minas Gerais, na qual as novidades da época não desqualificavam o peso das tradições. ${ }^{9}$

A propósito, cabe observar que a ênfase concedida à sua autonomia estética em relação à figura paterna parece estar associada ao cultivo de uma sociabilidade bem diversa daquela praticada pelo pai. Este último combinava em sua atuação a polidez europeia com uma clara afirmação da sua autoridade e das exigências hierarquizantes que daí decorriam - como foi visto tanto no mencionado episódio do casal de Traz, quanto na "explosão de Afrânio" com aquele seu desafeto, em Belo Horizonte. Penso que Afonso Arinos começa, pouco a pouco, deste momento em diante, a desenvolver uma relação mais intensa e ao mesmo tempo mais suave com o seu meio, pessoas e lugares, na medida mesmo em que começa a cultivar uma sociabilidade mais dialógica, aberta à surpresa, à diversidade e próxima a uma espécie de "diplomacia do espírito", no sentido utilizado por Marc Fumaroli (I998) para caracterizar uma das experiências dos salões da aristocracia francesa - tão admirada pelo nosso autor -, definida pelo tato nas maneiras e pela conversa elegante, que indicava um modo mais versátil, negociador e adaptável às várias posições em jogo na sociedade da época.

\section{O OUTRO LADO DA LUA}

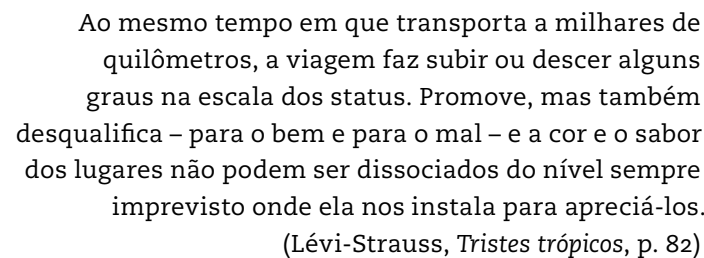

A hipótese seguida daqui por diante é a de que o ethos ao qual acredito que Afonso Arinos esteja mais pessoalmente associado não seria apenas aquele obtido e conservado pela valorização da tradição familiar, tal como sugerido na primeira parte, mas, sobretudo, o que ele cultiva pela incorporação daquele tipo de sociabilidade mais horizontal, suave e disponível à negociação, em condições de deslocar a centralidade até então concedida à figura do seu pai.

Se, então, o nosso autor se mostra agora capaz de avaliações mais autônomas, menos preocupadas em sustentar a tradição dos Melo Franco, aos poucos se fortalece nele, por esta via, conforme já mencionado, uma concepção pela qual qualquer tradição, para perdurar, precisa transformar-se e incorporar a novidade, necessitando assim de uma permanente reatualização para não se fossilizar, enferrujar e desaparecer. Creio ser justamente esta 
percepção da oportunidade de uma mudança, que ele conduzirá de um modo extremamente "diplomático", o que lhe permitirá integrar o circunstancial, o casual e a novidade à tradição familiar e mesmo a uma determinada concepção de tradição nacional, na medida mesma em que, para ele, suponho, ambas parecem estar estreitamente associadas.

A sugestão de que ele cultiva uma subjetividade e uma sociabilidade associadas a uma observação mais atenta às diferenças e a uma relação menos aristocrática e mais igualitária com o mundo estaria ligada a uma percepção da vida, no estrangeiro, como algo que se aproximaria da noção de exílio, de afastamento do seu torrão natal, experiência que o levaria a se afastar, até certo ponto, do ideal cosmopolita com que sempre vivera, chegando a demandar ou recomendar o cultivo de uma espécie de rusticidade. Cabe enfatizar que Afonso Arinos não nega em absoluto a importância do cosmopolitismo como capacidade de transitar entre fronteiras culturais; o que ocorre, portanto, é uma atenuação do afastamento em relação à sua própria cultura.

Neste sentido, as páginas de A alma do tempo em que constam as anotações do dia 9 de junho de 1960 nos permitem modular o argumento de uma relação unidirecional e sem solução de continuidade entre a ideia de Brasil e o "cosmopolitismo" de Afonso Arinos, ou seja, entre o que concebe como sua terra natal, e aquilo que lhe aparece, ao longo de sua vida intelectual, como legado da civilização ou como experiência do mundo. O momento, objeto de suas reflexões, era o início dos anos 1930, quando vivia com amargura seu isolamento no sanatório suíço e supunha extintos para sempre o sonho e a aventura.

Esta associação da vida no exterior com o sentimento do exílio parece articular as distâncias espaciais, temporais, culturais, sociais e políticas à ideia da perda da tradição, como se, quanto maiores fossem aquelas distâncias, maiores as forças a serem mobilizadas no sentido inverso, o da valorização da vida nacional, ou local. Naquelas páginas Afonso Arinos comenta a personalidade de Ribeiro Couto ${ }^{\text {IO }}$ e o que define como sua característica essencial: a conjunção perfeita entre sensibilidade - tato - e rusticidade, capaz de protegê-lo do que considerava "os dois mais insidiosos perigos do longo exílio: o despaisamento ${ }^{\text {II }}$ e a melancolia, sentimento que os alemães juntam em uma só e bela palavra: Heimweh" (Franco, I979a: 252). "A corrosão da vida no estrangeiro para que não altere ou destrua a personalidade nacional exige nervos fortes: um José Albano, um Gilberto Amado. O exemplo do contrário é Raul de Leoni" (Franco, I979a: 249-250).

Assim, a sensibilidade para mover-se em uma cultura estrangeira e a rusticidade para manter-se enraizado, esta dupla de contrários, é recomendada por Afonso Arinos no momento em que se autodefine poeta (menor), nacionalista e romântico, ao trocar versos com seu amigo diplomata, Ribeiro Couto. 
A almejada rusticidade, relacionada, como vimos na citação acima, à noção de força e vigor, demandava um movimento de $180^{\circ}$ em relação à sua experiência de até então, pois deveria não só exigir o fortalecimento da subjetividade como também evitar o excesso de seu cultivo, que poderia levar aos extremos do requinte, como o próprio Afonso Arinos evidencia em um minucioso registro dos seus estados d'alma em um determinado momento: "eu andava profundamente neurastênico, esgotado, insone, cheio de fobias e temores. Sentia uma sensação permanente de tontura, como se minha cabeça estivesse sempre oca ou cansada" (Franco, I979a: I87).

A ameaça do "exílio", a possibilidade de perda da identidade motivada pelo excesso de exposição a tradições externas, vinculava-se então a uma espécie de "enfraquecimento dos nervos", trazendo o risco de desenraizamento. Assim, o único antídoto capaz de evitar este caminho seria, precisamente, a solução encontrada por Ribeiro Couto, na qual, porém, a afirmação da rusticidade, dos valores locais, informa e convive com uma sensibilidade mais suave, educada e voltada para o mundo.

À luz dessas preocupações, a viagem a Ouro Preto, feita em I936,12 objeto de nossas atenções a seguir, parece, então, ganhar um sentido algo diverso daquele das viagens à Europa. Se por um lado ele se mantém fiel à atitude livresca que tivera anteriormente com relação ao exterior ("Nenhum de nós tinha ido a Ouro Preto, mas desde os vinte anos (e já tínhamos dobrado os trinta), através de leituras literárias, críticas, históricas, adquiríramos um conhecimento suficiente e um amor mineiro por aquelas ladeiras, aquelas pontes, aqueles chafarizes, que só nos faltava, agora, ver") (Franco, I980: I7), por outro, acredito que, pelo menos em parte, sua ligação com o Modernismo faça com que essa disposição de busca "calma, deliberada, refletida" do que é estável e permanente nas nossas tradições tome um rumo mais lírico e aventuroso, do acaso, da descoberta e da invenção, rumo igualmente atribuído à própria cidade:

Felizmente, a poesia invencível, inexprimível, invasora, da antiga capital das Minas, destruiu boa parte de tais planos de defesa [a dose de raciocínio e de crítica com que pretendiam conter o impacto emocional produzido pelo encontro com a cidade]. Em Ouro Preto ninguém se defende contra a agressão da poesia (Franco, 1980: 19).

Associo, portanto, esta viagem a Ouro Preto, esse grand tour interno de Afonso Arinos, à percepção da ameaça que pode representar a mera reprodução da cultura clássica e até a adesão a uma modalidade excessiva e mais radical de cosmopolitismo, como aquela à qual se referia, melancolicamente, nas belíssimas páginas do "Intróito" de A rosa de ouro quando falava do seu tio e padrinho João de Melo Franco, o qual fizera parte de uma geração belle époque, já desaparecida, que representara apenas essas "pequenas vagas que encrespam por instantes antes de se perderem no oceano do esquecimento" (Franco, 2007: 22). 
Desse modo, considerando a visita dos modernistas a Ouro Preto em I924 como representativa desse grand tour interno - embora houvesse outras ${ }^{\text {I3 }}$ que possivelmente estavam na lembrança de Afonso Arinos quando visita à cidade em I936 - é preciso salientar que esta viagem, em função mesmo da sua ênfase na busca do autêntico e do nacional, dá o tom e o contexto da instabilidade e da ruptura parcial de Afonso Arinos com as tradições europeizantes adquiridas por intermédio do seu contato com os seus familiares. Esse contexto de instabilidade se constitui tanto objetivamente através das ameaças ao patrimônio material que é Outro Preto, em virtude das quais, diga-se de passagem, é criado o Serviço do Patrimônio Histórico e Artístico Nacional (SPHAN), ${ }^{\mathrm{I}}$ quanto através da disputa acerca do significado das relações entre o nacional e aquelas tradições europeias, disputa que dá a impressão de sumarizar as principais questões em debate na época. A partir dessas considerações, torna-se possível ampliar um pouco o significado que atribuí à viagem de Afonso Arinos ao interior do país: ela torna-se tanto uma descoberta das tradições especificamente nacionais, nas quais ele enfaticamente se inclui - e aos seus - quanto a adoção de uma forma específica de entendimento daquelas relações entre o nacional e o estrangeiro, que passa por uma via de moderação da ênfase excessiva posta em um ou outro daqueles dois polos na formação da cultura brasileira.

Nesse sentido, não penso haver em Afonso Arinos uma opção pelo nacional em detrimento do universal, ou seja, da cultura clássica erudita, nem por uma fusão, na qual as características de um e de outro se dissolveriam em uma espécie de síntese. Em vez de reencontrar em Ouro Preto uma marca singular das tradições brasileiras, o que se percebe no seu texto é precisamente uma ideia de intercâmbio da cultura ocidental com as tradições nacionais, apontando para uma situação na qual o local e o universal parecem se articular de uma maneira particularmente feliz. Penso que o que se segue tornará mais claro o modo como ambos, o universal e o singular, se harmonizam na narrativa de Roteiro lírico de Ouro Preto.

Durante esta "peregrinação laica" - lembremos que a viagem foi feita na Semana Santa - a carga de ancestralidade que é atribuída a Ouro Preto mostra-se capaz de mobilizar lembranças repletas de valor afetivo. Afonso Arinos pergunta-se, antes da chegada, "Em que noite, em que terra eu $u^{15}$ iria desembarcar?" É "ao Ouro Preto do princípio da República, a grave cidade dos funcionários, da literatura e da política. O Ouro Preto dos meus avós e dos meus pais" (Franco, I980: 2I), responde, passando então a reconstituir inúmeras genealogias das famílias do lugar e, assim, ao lado de sua preocupação com o patrimônio material de Ouro Preto, a patentear o esforço em recuperar, manter e transmitir um patrimônio imaterial do qual, reafirmo, ele se considera parte.

Todavia, se o modelo clássico sabidamente aponta para uma viagem ao encontro do que já é conhecido, o périplo dos personagens de Roteiro lírico pe- 
las ruas de Ouro Preto, ao contrário, desvia-se desse modelo e tenta caminhos alternativos que levem à experiência, à novidade e ao contato com o acaso.

Arinos e suas personas, a do narrador e a do poeta, chegam à noite, ${ }^{16}$ perambulam por uma Ouro Preto onírica e se veem diante de experiências inusitadas. Encontram personagens anacrônicos, tal como o estudante que toca Schumann ao violino, evocam outros da época do Império como Tiradentes, Tomaz Antonio Gonzaga, Cláudio Manoel da Costa, Marília e Dirceu. Será a partir desse cenário desconhecido, inesperado, que irromperá uma outra Ouro Preto que o leitor irá descobrir pelas mãos do poeta: a Ouro Preto dos bares, da boemia, das bebedeiras.

A importância assumida pelo poeta e pelo seu grupo particular de boêmios locais deu a Afonso Arinos o clímax do enredo de Roteiro lírico: o episódio em que um desconhecido em estado de coma etílico, mas "um grande ouro-pretano", nas palavras do personagem de Pedro Nava - o poeta - é levado por este para o quarto que ocupava, juntamente com o narrador e com o filósofo. ${ }^{17}$ Arma-se a confusão quando o poeta tenta despir o desconhecido e colocá-lo sobre a cama desocupada, sob os protestos do filósofo. O bêbado, "após gritar com voz pastosa que defenderia até a morte a sua honra, [passa], sem transição, a vomitar com pompa e alarido" (Franco, I980: 43).

E o episódio não terminaria aí. Após serem expulsos do quarto pelo filósofo,

[a]conteceu, porém, que o poeta e o seu fardo, ao chegarem à calçada, saindo do hotel encontram o automóvel que o viajante [também hóspede do hotel] mandara buscar, a fim de o levar à Estação. Sem nenhuma surpresa o poeta se aboletou no veículo, com o companheiro inconsciente. Chega o homem do comércio e, furioso, quer enxotá-los. Mas o poeta ri-lhe na cara, e o obriga a ir ao lado do chofer, por especial obséquio. Bem avisado foi o pobre homem em obedecer, porque assim, deixou de receber o vômito abundante que, já antes de partir o carro, o desconhecido prodigalizou sobre as suas malas, colocadas no interior do automóvel.

Subindo lentamente, para o Carmo, vou pensando que só o amor de Ouro Preto é capaz de fazer galgar ladeiras a um pobre turista tresnoitado (Franco, 1980: 45).

A narrativa prossegue com a tentativa do narrador - provavelmente o personagem de Afonso Arinos - de restituir a ordem, a calma (segue a pé, pois "o automóvel confunde tudo, na sua rapidez") e o sentido (roteirizar a história de Ouro Preto) à visitação da cidade mineira.

Durante todo o episódio, o narrador parece querer evadir-se da cena. Primeiro, declara: "Resolvi instantaneamente não tomar partido" (Franco, I980: 43); em seguida, como se já bastasse tanto vômito e imprecação, ele busca trazer seu leitor para algo mais elevado e passa a relatar sua primeira visão da Igreja de Nossa Senhora do Carmo ao amanhecer, que "em cima do morro, debaixo do céu, muito branca, prodigiosamente branca, desprendia-se da terra, começava a voar na luz divina" (Franco, I980: 45). 
Todavia, observando mais de perto, esta suposta indiferença ao conflito pode ser entendida em outra chave, uma chave que aponta, aliás, para um possível diálogo com importante parcela do ensaísmo brasileiro da época. ${ }^{18}$

Assim, por um lado, o antagonismo entre o filósofo e o poeta e a resposta do segundo ao ultimato do primeiro, permite que vejamos em toda essa desmesura um sinal do excesso de cordialidade que movia o tresloucado personagem: "ouvindo aquela enormidade o poeta lhe disse, com infinita doçura: 'Você é um mau amigo e um mau caráter. Mas eu sou assim, sou solidário até às últimas'” (Franco, I980: 43).

Por outro, onde o narrador diz "não tomar partido", entenda-se polidez, respeito às regras, senso de medida, comportamento diplomático e civilidade. As coisas parecem se apresentar como se os excessos, tanto se revelassem mutuamente, sem que um termo tivesse que excluir o outro, como, ao mesmo tempo, necessitassem de uma certa contenção. Isto é, como se a porção de civilidade do narrador temperasse o excesso de cordialidade do poeta e vice-versa.

No fundo eu admirava a ternura do poeta, a sua humanidade, o seu sentimento de cooperação. Mas, por outro lado, sentia-me vagamente irritado, com aquele despertar insólito, aquele escândalo no hotel, com grunhidos e vômitos (Franco, I980: 44).

Mas, para Afonso Arinos, essa cordialidade é acionada pelo clima lírico, onírico, boêmio da cidade, ou seja, por um tipo de sociabilidade especificamente local (lembremo-nos: é um ouro-pretano ilustre que é levado ao quarto pelo poeta). E nesse sentido, estas são características que precisavam ser reconhecidas pelos seus leitores naquele momento.

Diferentemente de Genebra, onde, como vimos, os padrões de sociabilidade eram estritamente regulados e permitiam ao autor exercitar o seu ballet social como filho do ilustre Afrânio, Ouro Preto, com seu lado desmesurado, lhe permitirá exercitar sua diplomatie em condições outras, se não adversas: mesmo tresnoitado não se altera, cede o quarto para o poeta, e o fato de não se alterar, como vimos, não significa indiferença: corre para a janela para inteirar-se do resultado da expulsão que o filósofo promovera e o seu comentário não exprime qualquer sinal de censura, pelo contrário, aponta para o que teria sido um "final feliz" do incidente, ou seja, o fato do caixeiro viajante ter sentado no banco da frente e escapado do vômito do bêbado. Mas não a sua bagagem, ou seja, não há como sair ileso da experiência inerente Ouro Preto.

Em suma, em Roteiro lírico de Ouro Preto Afonso Arinos conjuga o significado de roteiro como guia de viagem com o de "auto", em seu sentido religioso, teatral e público. E o personagem de Pedro Nava, o poeta, com seu comportamento anárquico, caótico e intemperante, constitui o contraponto manifesto do ideal de ordem e temperança demonstrado por Afonso Arinos até então. Além disso, esse comportamento parece dar ao nosso autor a opor- 
tunidade de exercitar aquela sensibilidade diplomática, baseada no tato, que irá caracterizar a sua atuação pública.

Por fim, é possível entender a cordialidade tanto como ameaça, na medida da sua incivilidade, à qual poderiam estar de certo modo associados os excessos de temperamento do pai, subjugando a expressão da individualidade do filho, quanto, em sua versão moderada, como o fundamento necessário para o surgimento de vínculos que impliquem intimidade, generosidade e calor. Também a civilidade conhece em Afonso Arinos pelo menos duas versões, aquela de um requinte extremo de figuras que se desenraizam e, consequentemente, acabam por desaparecer em seu solo natal, e uma outra que se manifesta pelo exercício de uma atitude de tolerância com relação à existência de individualidades diferentes e a necessidade de conviver com elas.

Recebido em 06/05/2013|Aprovado em 23/09/2013

Carmen Lucia Felgueiras é doutora em Sociologia pelo Instituto Universitário de Pesquisas do Rio de Janeiro (IUPERJ) e professora associada do Departamento de Sociologia da Universidade Federal Fluminense (UFF). Suas principais áreas de interesse são:

interpretações do Brasil em perspectiva comparada, narrativas de viagens e diplomacia. Publicou partes da sua tese de doutorado em revistas como Estudos Históricos e Revista da Biblioteca Nacional. 


\section{NOTAS}

I Afonso Arinos que inicia sua vida profissional no jornalismo, ao lado de Carlos Drummond de Andrade no Diário de Minas, em I927; foi promotor de Justiça na comarca de Belo Horizonte; professor universitário, deputado federal e senador, em décadas de vida política militante e representativa; membro da Academia Brasileira de Letras; ministro das Relações Exteriores do governo Jânio Quadros; e, em I962, no governo parlamentar; secretário do governo Magalhães Pinto, em I964, encerrando sua participação na vida pública na Constituinte de 1988.

2 Esclareço desde já que estou considerando relatos de viagens no sentido literal do termo, dos quais constam, naturalmente, os relatos de viagens propriamente ditos, mas também os livros de memórias, diários e mesmo de obras de cunho histórico e sociológico produzidos por Afonso Arinos.

3 Baldassar Castiglione, autor de O cortesão, tratado de retórica do século XVI, nos permite uma melhor compreensão deste sentimento de naturalidade de Afonso Arinos, visto que a própria ênfase em uma concepção hierárquica de sociedade implica uma compatibilização entre desenvoltura civil e dissimulação do esforço em bem se conduzir. Ver Pons (1999).

4 Vale apenas mencionar a enorme importância de Ana Guilherminha Rodrigues Alves Pereira (Anah), a qual conhece em I925 e com quem vem a se casar em I928, para o que estou tratando como um processo de automodelagem. Se a volta à Europa ainda estava em seus planos em I925, o amuo da namorada fez com que rasgasse o telegrama do pai autorizando a viagem, se passasse nos exames, e o jogasse no rio Piabanha (Franco, I979a:173).

5 Dentre os intérpretes da obra de Afonso Arinos que valorizaram este aspecto da viagem de Afonso Arinos à Europa está Berenice Cavalcante (2006).

6 Até o princípio do século essa predominância do bacharelismo vigorou na vida do país e, por consequência e com maior razão, dentro das Faculdades de Direito.(Franco, I979a, p.73).

7 Afonso Arinos publica dois poemas, "Paisagem de brinquedo" e "Copacabana" em Estética (I924-I925), revista 
modernista dirigida por Prudente de Moraes, neto e Sergio Buarque de Holanda, com a qual também colaborou um extenso grupo de intelectuais vinculados ao movimento. Aliás, seu envolvimento na revista ultrapassa essa limitada colaboração, tendo, inclusive, buscado recursos entre seus amigos em Minas para financiá-la.

8 Trata-se aqui do episódio em que Afranio de Melo Franco destrata Liminha (Augusto de Lima Jr.) por atacar o filho em seu jornal, motivado tanto pelo favoritismo de Antonio Carlos na nomeação de Afonso Arinos para promotor no Rio de Janeiro, como em resposta a uma crônica que este publicara em O Jornal, do Rio de Janeiro, a propósito de uma viagem a Sabará. Comentando o fato, o pivô do incidente dirá: "o jornal do Liminha estampou violentos revides contra mim, destinados a mostrar o nosso horror familiar às tradições mineiras" (I979a: 200), o que, a seu ver, apenas exprimia a hostilidade de grupos locais contra o seu pai.

9 Como sugerem Gonçalves (I996) e Marques (20II), a implementação dos ideais modernistas em Minas Gerais, ao valorizar a contribuição da estética barroca, implica uma sutil e complexa recuperação dos valores do passado.

Io Afonso Arinos interfere na rixa, ocorrida por motivos literários, entre Ribeiro Couto e o cônsul brasileiro em Marselha, Mateus de Albuquerque, conseguindo a remoção do primeiro para Paris, antes negada ("fiquei uma fera"), na forma de um pedido pessoal ao pai, então Ministro das Relações Exteriores.

I I "Despaisamento", assim como "país", pode ser interpretado no sentido medieval do termo, como torrão natal, e não como estado- nação (Ver Kantorowicz, I965).

I2 As dificuldades que o intervalo temporal entre os relatos das experiências podem representar para a esta interpretação me foram apontados pela professora Heloisa Pontes, quando da exposição da versão preliminar deste texto no $36^{\circ}$ Encontro Anual da ANPOCS. Embora não pretenda es gotar todas as implicações do problema nesta nota, gostaria de observar que não só Roteiro lírico de Ouro Preto, de I937, permanece sem reedição até o momento da publicação de A alma do tempo, em I979, como também partes dele constam de várias passagens do livro de memórias, o que 
600

talvez tenha por efeito minimizar este intervalo, produzindo uma espécie de iluminação recíproca que torna ambos os textos relativamente contemporâneos. Por outro lado, entendo que Roteiro lírico, escrito em um momento posterior às primeiras viagens à Europa, também possa funcionar aqui como uma primeiro esboço das mudanças subjetivas do autor que esta interpretação sugere.

I3 Como as de Olavo Bilac, em I893, e a de Alceu de Amoroso Lima, em I9I6, ambas mencionadas por Braga (s/d).

I4 Sem dúvida, parte da importância da viagem estaria em identificar tais ameaças. Afonso Arinos pontua a narrativa com registros dessa observação e das providências que tomou. Em certas passagens a narrativa de Roteiro lírico chega a assumir um tom de relatório.

I5 É oportuno chamar a atenção aqui para o uso da primeira pessoa, pois Afonso Arinos, autor de Roteiro Lírico, coloca-se simultaneamente na figura dos seus diferentes personagens, o "narrador", o "poeta", o "filósofo" e do "místico".

I6 Só bem mais adiante é que ele irá contrastar essa Ouro Preto noturna com a outra, diurna. "Eu ainda não vira Ouro Preto de dia, e a cidade misteriosa, pesada de romances e de tragédias, que nós percorrêramos durante a noite, parecia-me, agora, outra, repousada e matronal" (Franco, 1980: 33).

I7 O personagem de João Gomes Teixeira.

I8 Afonso Arinos dialoga aqui com dois importantes autores. Um deles é Paulo Prado, cujo ensaio Retrato do Brasil é publicado em 1928, e Sérgio Buarque, autor de Raízes do Brasil, que vem a público no mesmo ano da viagem a Ouro Preto, 1936. 


\section{REFERÊNCIAS BIBLIOGRÁFICAS}

Bloch, R. Howard. (1983). Etymologies and genealogies. A literary anthropology of the French middle ages. Chicago/Londres: The University of Chicago Press.

Braga, Vanuza Moreira. (s/d). Ouro Preto e as políticas de preservação no Brasil. I Jornada Discente do PPHPBC. Rio de Janeiro: CPDOC/FGV.

Buzard, James. (2002). The grand tour and after (I660-I840). In: Hulme, Peter \& Yougs, Tim (orgs.). Travel writing. Cambridge: Cambridge University Press.

Cavalcante, Berenice. (2006). Passaporte para ofuturo. Afonso Arinos de Melo Franco, um ensaísta da República. Rio de Janeiro: Vieira e Lent.

Elias, Norbert. (200I). A sociedade de corte. Rio de Janeiro: Zahar.

Franco, Afonso Arinos de Melo. (2007). Rosa de ouro. Belo Horizonte: Ed. UFMG.

Franco, Afonso Arinos de Melo. (I982). Amor a Roma. Rio de Janeiro: Nova Fronteira.

Franco, Afonso Arinos de Melo. (1980). Roteiro lírico de Ouro Preto. Brasília: Ed. UnB.

Franco, Afonso Arinos de Melo. (I979a). A alma do tempo. Memórias. Rio de Janeiro: Livraria José Olympio/INL-MEC. Franco, Afonso Arinos de Melo. (I979b). Diário de bolso. Rio de Janeiro: Nova Fronteira.

Fumaroli, Marc. (1998). La diplomatie de l'esprit. Paris: Hermann.

Gonçalves, José Reginaldo. (I996). A retórica da perda. Os discursos do patrimônio cultural no Brasil. Rio de Janeiro: Editora UFRJ/Ministério da Cultura-IPHAN.

Holanda, Sérgio Buarque de. (2006). Raízes do Brasil. São Paulo: Companhia das Letras.

Kantorowicz, Ernst. (1965). Pro Patria Mori in medieval political thought. In: Selected Studies. Nova York: J. J. Augustin Publisher.

Marques, Ivan. (20II). Cenas de um modernismo de província. Drummond e outros rapazes de Belo Horizonte. São Paulo: Ed. 34/FFLCH-USP. 
602

Paiva, Valéria. (2009). A identidade como obra coletiva em O Cortesão, de Baldassare Castiglione. Tempo Social, Revista de Sociologia da USP, 2I, I, p. 9I-III.

Pons, Alan. (1999). La rhétorique des manières au XVIe siècle em Italie.. In : Fumaroli, Marc (org.). Historie de la Rhètorique dans la Europe Moderne. I450-I950. Paris: Presses Universitaires de France, p. 4II-429.

Prado, Paulo (1997). Retrato do Brasil. Ensaio sobre a tristeza brasileira. São Paulo: Companhia das Letras.

Simmel, Georg. (2002). Sobre la aventura. Ensayos de estética. Barcelona: Península.

Simmel, Georg. (1988). Philosophie de la modernité I: la femme, la ville, l'individualisme. Paris: Payot.

Simmel, Georg. (1977). Sociología: estudios sobre las formas de socialización. Madri: Revista de Occidente.

Simmel, Georg. (I97I). Sociability. In: Levine, Donald (org.). On individuality and social forms. Chicago: University of Chicago Press, p. I27-186.

Waizbort, Leopoldo (org.). (I999). Dossiê Norbert Elias. São Paulo: Edusp. 
Palavras-chave Melo Franco; Viagens;

Subjetividade;

Sociabilidade; Patrimônio cultural.
Afonso Arinos de

\section{LUA E ESTRELA: EXPERIÊNCIA E UNIVERSALIDADE NAS VIAGENS DE AFONSO ARINOS DE MELO FRANCO}

\section{Resumo}

Este artigo aborda o pensamento de Afonso Arinos de Melo Franco utilizando seus relatos de viagens para destacar um aspecto pouco explorado pela bibliografia, que é o seu diálogo com o Modernismo e a sua relação com a cultura nacional. As viagens serão as que Arinos realizou no início da década de 1920 à Europa e aquela feita em I936 a Ouro Preto. A primeira é fortemente marcada pela expectativa do pai de que completasse sua educação através de uma experiência capaz de lhe proporcionar maior intimidade com a cultura clássica. Já em Ouro Preto, em vez de reencontrar uma marca singular das tradições brasileiras, o que se percebe no relato de Afonso Arinos é a ideia de intercâmbio da cultura clássica com as tradições nacionais, apontando para uma situação na qual o local e o universal parecem se articular de uma maneira particularmente feliz.

THE MOON AND THE STAR: EXPERIENCE AND

\section{UNIVERSALITY IN AFONSO}

\section{ARINOS DE MELO FRANCO'S TRAVELS}

Keywords Afonso Arinos de Melo Franco; Travel; Subjectivity; Sociality; Cultural patrimony. much explored aspect in the bibliography, which is its

\section{Abstract}

The article discusses the ideas of Afonso Arinos de Melo Franco using his travel reports to highlight a not very dialogue with modernism and its relationship with the national culture. The trips will be the ones that Arinos held at the beginning of I92os in Europe and one made in 1936 to Ouro Preto. The first one is strongly influenced by the expectation of his father to complete his education through to an experience which would be able to provide him a greater intimacy with the classical culture. However, in Ouro Preto, instead of rediscovering a unique brand of Brazilian traditions, what is perceived in the narrative of Afonso Arinos is the idea of an exchange between classical culture and national traditions, pointing to a situation in which the local and the universal seem to be articulated in a particularly happy way. 